\title{
Neurocutaneous melanosis presenting with hydrocephalus and malignant transformation: case-based update
}

\author{
F. Sharouf ${ }^{1}$ (D) M. Zaben ${ }^{1} \cdot$ A. Lammie ${ }^{1} \cdot$ P. Leach $^{2} \cdot$ M. I. Bhatti ${ }^{2}$
}

Received: 1 November 2017 / Accepted: 21 May 2018 / Published online: 12 June 2018

(C) The Author(s) 2018

\begin{abstract}
Introduction Neurocutaneous melanosis (NCM) is a sporadic condition characterised by congenital melanocytic nevi and melanocytic thickening of the leptomeninges. It is believed to result from congenital dysplasia of melanin-producing cells within the skin and leptomeninges. The management of cutaneous manifestations remains controversial; for neurological manifestations, outcome remains poor even with the use of radiotherapy and chemotherapy.

Patients and methods We describe the case of a 5-month-old boy who presented with giant congenital melanocytic nevus and hydrocephalus. MR imaging and CSF immunohistochemistry confirmed leptomeningeal melanosis. We discuss the diagnosis, treatment and prognosis of this rare disorder in the light of recent published literature.

Results Patient required placement of right-sided ventriculoperitoneal shunt to control hydrocephalus. The patient tolerated the procedure well and was discharged home with normal neurological function. A presumptive diagnosis of NCM was made based on the MR characteristics, CSF cytology and clinical presentation. He received trametinib, a MAPK/Erk kinase inhibitor for 7 months. At 30 months of age, he developed left-sided weakness and status epilepticus requiring paediatric intensive care unit admission and ventilator support. The patient eventually succumbed to malignant transformation of leptomeningeal disease.

Conclusion Cutaneous manifestations of NCM are usually congenital, and neurological manifestations develop early in life. Patients with large or multiple congenital nevi should therefore be investigated early to facilitate treatment. MR imaging is the investigation of choice which can further assist in performing biopsy. Symptomatic NCM is refractory to radiotherapy and chemotherapy and has a poor prognosis. A multidisciplinary approach is necessary in the management of NCM patients.
\end{abstract}

Keywords Neurocutaneous melanosis $\cdot$ Hydrocephalus $\cdot$ Melanocytic nevi $\cdot$ Leptomeningeal melanosis

$\begin{array}{ll}\text { Abbreviations } \\ \text { NCM } & \text { Neurocutaneous melanosis } \\ \text { CNS } & \text { Central nervous system } \\ \text { HGF/SF } & \text { Hepatocyte growth factor/scatter factor } \\ \text { NRAS } & \text { N-type Rat Sarcoma gene } \\ \text { MAPK } & \text { Mitogen-activated protein kinase } \\ \text { MEK } & \text { MAPK/Erk kinase } \\ \text { FDA } & \text { The Food and Drug Administration } \\ \text { CSF } & \text { Cerebral spinal fluid } \\ \text { DWC } & \text { Dandy-Walker complex } \\ \text { PET } & \text { Positron emission tomography }\end{array}$

F. Sharouf

Sharouffh@cardiff.ac.uk

1 University Hospital of Wales, Department of Neurosurgery, Cardiff University, Heath Park, Cardiff CF14 4XW, UK

2 University Hospital of Wales, Cardiff, UK
PICU Paediatric intensive care unit

DLE Diffuse leptomeningeal enhancement

\section{Introduction}

Neurocutaneous melanosis (NCM) is a rare syndrome characterised by congenital melanocytic nevi and melanocytic thickening of the leptomeninges [32]. Although mostly sporadic, a few familial cases of NCM have been reported [22]. In most cases, NCM presents with symptoms of raised intracranial pressure [1]. NCM is believed to result from congenital dysplasia of melanin-producing cells within the skin and leptomeninges [20].

Two thirds of patients with NCM have a giant congenital melanocytic nevus, and the remaining third have multiple small lesions [19]. Nevi are usually present at birth, but more may develop later in life. Almost all nevi have a lumbosacral (bathing trunk) distribution [10]. 
In the majority of cases, NCM exhibits symptoms of raised intracranial pressure within the first 2 years of life [20]. As in the case reported here, most cases present with symptoms and signs of increased intracranial pressure including irritability, lethargy, recurrent vomiting, increased head circumference, bulging anterior fontanelle and photophobia [1]. Hydrocephalus develops in two thirds of patients.

\section{Historical background}

Although first described by Rokitanski in 1861 [31], the term neurocutaneous melanosis was coined by van Bogaert in 1948 [38]. The initial diagnostic criteria of NCM included large or numerous pigmented nevi without malignant transformation [12], which was later revised to include malignant transformation and distant metastasis [10]. Since its first description, 100 or so cases have been described in the English literature [28].

NCM is a sporadic syndrome with few reported familial cases [9, 13]. Animal models of NCM have been developed. Transgenic mice overexpressing hepatocyte growth factor/scatter factor (HGF/SF) demonstrate extensive pigmented nevi in both skin and leptomeninges of the central nervous system, thus resembling human NCM. HGF/SF are growth factors that control the proliferation of neural crest melanocytes during embryogenesis [37]. Dysregulation of these growth factors may explain associated cystic malformations of the posterior fossa such as the Dandy-Walker complex (DWC) [37].

Oncogenic missense mutations (affecting the NRAS gene) have been identified in affected neural and cutaneous tissue in NCM patients. However, these mutations were not found in unaffected tissues and blood. The mutations are thought to be the result of somatic mosaicism, which occurs in a progenitor cell in the developing neural crest or neuroectoderm [21]. This suggests that these mutations would be lethal if they occurred in germ line cells [21].

The resultant phenotype is dependent upon the type of mutation, affected cells and timing [15]. NRAS mutations have only been found in benign melanocytic nevi. This indicates that they are of themselves insufficient for malignant transformation to occur. Given that malignant transformation is an indicator of poor prognosis in NCM (as discussed in prognosis and outcomes), a better understanding of molecular genetic pathogenesis is required [39]. NRAS mutations could represent a potential therapeutic target for NCM [27]. NRAS melanomas are thought to proliferate through the MAPK pathway which could be inhibited by MEK inhibitors. Trametinib for example, a MEK inhibitor, has been approved by The Food and
Drug Administration (FDA) for the treatment of certain NRAS-mutated melanomas [18].

The histopathological patterns of NCM cutaneous lesions are indistinguishable from those seen in congenital melanocytic nevi without CNS involvement. Nevus cells spread into the dermis and encircle nerves and blood vessels [19, 26]. Leptomeningeal melanosis is most evident in areas of physiological melanin distribution such as the base of the brain, the ventral surface of the pons, cerebral peduncles, the medulla and cerebellum [10]. Several features have been identified to distinguish meningeal melanosis from melanoma which can develop in about half of the cases [30]. Necrosis, invasion of basal lamina and cell atypia can distinguish melanoma from melanosis. Although the prognostic significance of this distinction is unclear [20], CSF cytology is used to investigate malignancy but its sensitivity is reported to be around $40 \%$ [20].

\section{Clinical presentation}

A large congenital melanocytic nevus with bathing trunk distribution is observed in two thirds of patients with NCM [19]. In the remaining third of patients, multiple smaller melanocytic nevi without a single large lesion are found. Nevi are dark pigmented lesions circumscribed with irregular borders that can be raised or flat. They are usually present at birth, although new nevi can develop later in life [6].

Most patients exhibit neurological symptoms by 2 years of age; however, some cases may present during the second or third decade of life [20]. Two thirds of patients will present with neurological signs and symptoms due to increased intracranial pressure such as irritability, lethargy, headache, vomiting, photophobia, papilledema bulging anterior fontanel and enlarging head circumference [1], as in our exemplary case. Seizures, aphasia and motor or cranial nerve palsies may develop in patients with intracranial melanocytic tumours (see Table 1) [19]. Patients who present late in life may have spinal involvement which may result in myelopathy, radiculopathy and bowel or bladder dysfunction [19].

We reviewed the literature by searching PubMed using the terms "neurocutaneous melanosis" and "hydrocephalus." We included only publications in English dated 01/01/2000 to present as illustrated in Table 1.

Neurocutaneous melanosis can be linked to other neurocutaneous disorders, such as neurofibromatosis type 1 and Sturge-Weber syndrome [10].

The association of Dandy-Walker Syndrome and NCM is a rare complex, and to our knowledge only 24 cases have been reported up do date $[5,11,20,26]$. 


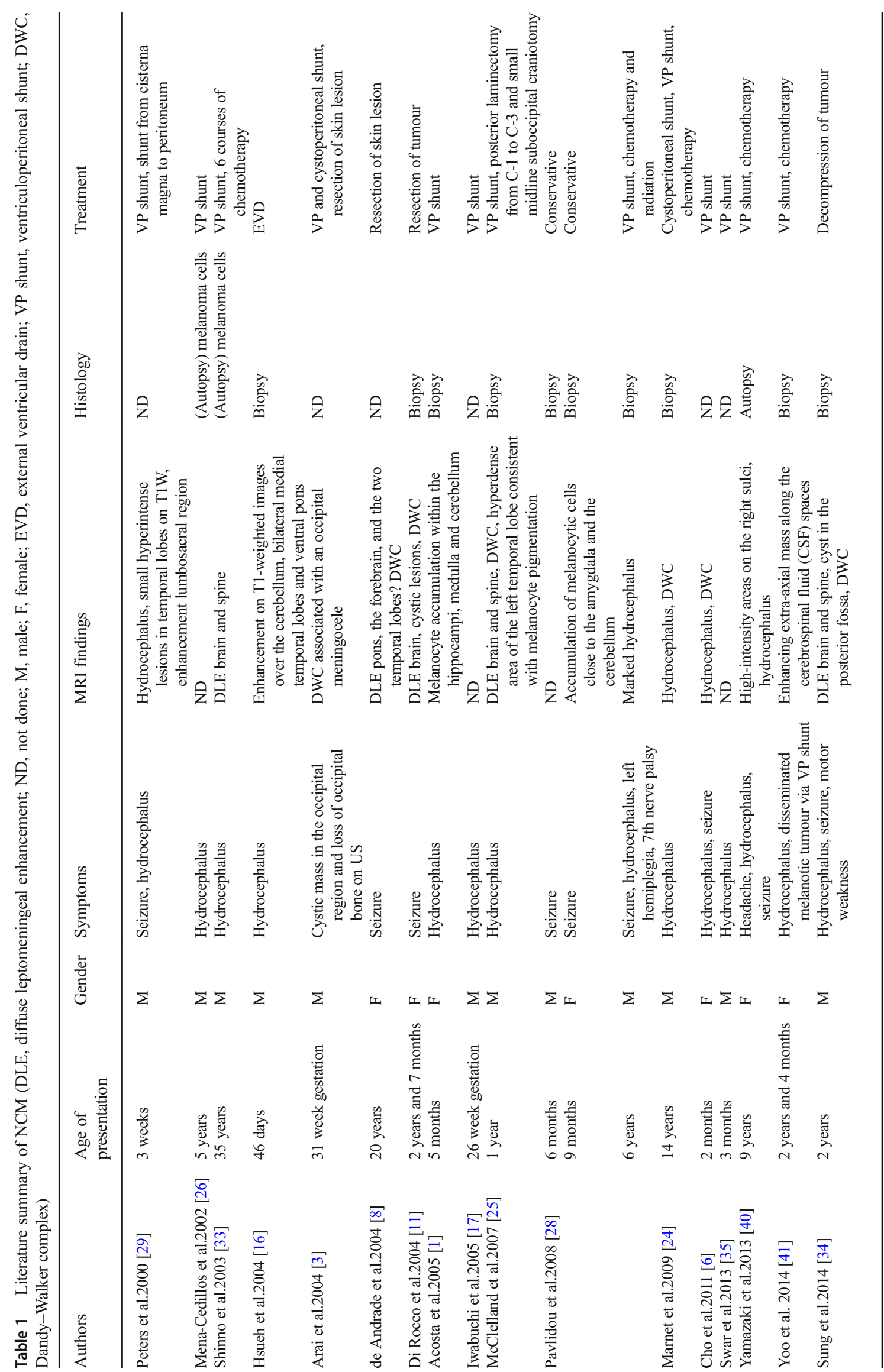


DWC may be due to the leptomeningeal anomalies of NCM, which could hinder the normal development of the cerebellum and IV ventricle [19]. Two theories have been proposed to explain the link between leptomeningeal melanosis and DWC. Chalpouka et al. [5] suggest that leptomeningeal melanosis restricts the ability of primitive meningeal cells from inducing normal deposition of the extracellular matrix, neuronal migration and formation of CSF resorption pathways, resulting in the formation of posterior fossa cysts and vermian aplasia characteristic of DWC. Barkovich et al. [4], on the other hand, have proposed that leptomeningeal melanosis interferes with normal ectodermal-mesodermal interaction, causing abnormal formation of the cerebellum and fourth ventricle.

\section{Diagnosis}

Criteria for the diagnosis of NCM were first proposed in 1972 and included large or numerous pigmented nevi in patients without malignant transformation in cutaneous lesions and without evidence of melanoma except in the leptomeninges [12].

Since then, both malignant transformation of cutaneous nevi and distant metastases of leptomeningeal melanoma have been recorded [10]. This led to revision of the diagnostic criteria which currently comprise (1) large (diameter more than $20 \mathrm{~cm}$ in adults or $6-9 \mathrm{~cm}$ in infants) or numerous (three or more lesions) congenital nevi in association with leptomeningeal melanosis or melanoma; (2) no evidence of cutaneous melanoma, except in patients with histologically benign meningeal lesions; and (3) no evidence of meningeal melanoma, except in patients with histologically benign cutaneous lesions [19].

Confirmation of the diagnosis is still based on histological findings, often only at autopsy. Hairy nevi can also be found in up to $40 \%$ of cases of primary malignant melanoma of the leptomeninges [2]. In rare cases of leptomeningeal melanomatosis, tumour cells may be amelanotic (unpigmented) and patient may not present with NCM [36]. This highlights the difficulty of obtaining an histological diagnosis in these conditions.

On the other hand, MR imaging may allow a presumptive diagnosis of CNS melanosis to be made [13, 22]. Leptomeningeal melanosis demonstrates a distinctive hyperintensity on T1-weighted MR images and a hypointensity on T2-weighted MR images [4, 10]. Patients may also present with intraparenchymal lesions without meningeal involvement [32].

\section{Management}

For cutaneous manifestations, the management remains controversial. Some dermatologists support prophylactic surgical excision of large melanocytic nevi to reduce the risk of malignant transformation, which occurs in 5 to $15 \%$ of patients [19], and to improve cosmetic appearance. For neurological manifestations, outcome remains poor even with the use of radiotherapy and chemotherapy [7,23]. Early neurosurgical intervention, however, can assist in tissue diagnosis and has the potential to effect early decompression [13]. The usual surgical intervention is shunt insertion with a filter to prevent potential seeding into the abdominal space [29].

\section{Prognosis and outcomes}

Prognosis in NCM is generally poor, with half of patients dying within 3 years of the onset of neurological symptoms [19]. However, the course of asymptomatic patients is variable and unpredictable $[14,20]$. The worst prognosis is seen in NCM patients with Dandy-Walker complex (DWC). DWC is thought to be a marker of melanocytic
Fig. 1 Giant hairy nevus in bathing trunk distribution
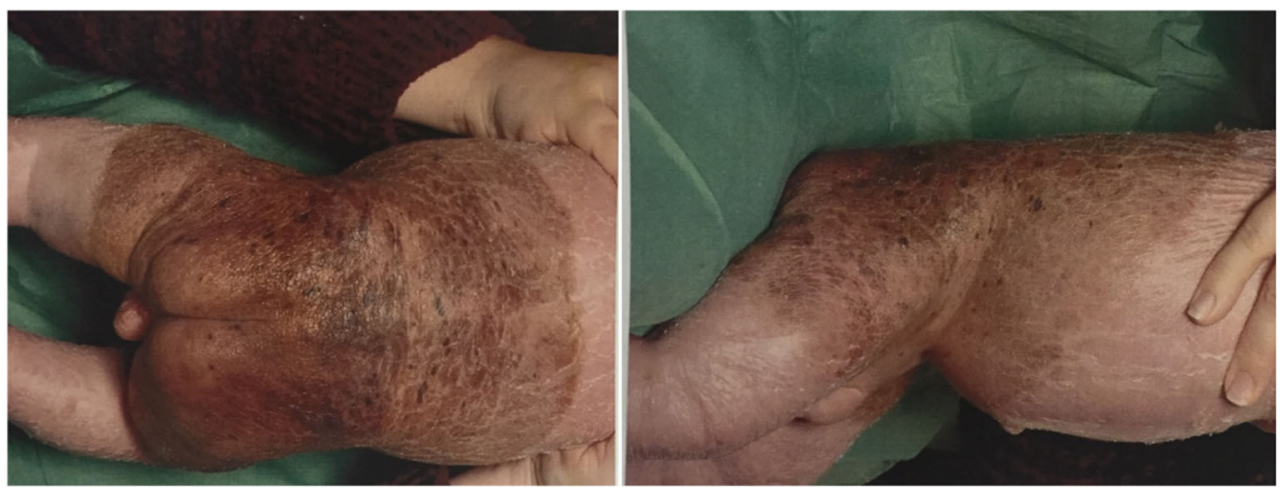
Fig. 2 Axial CT. a

Communicating hydrocephalous and transependymal oedema. b Decompressed ventricles after shunt placement

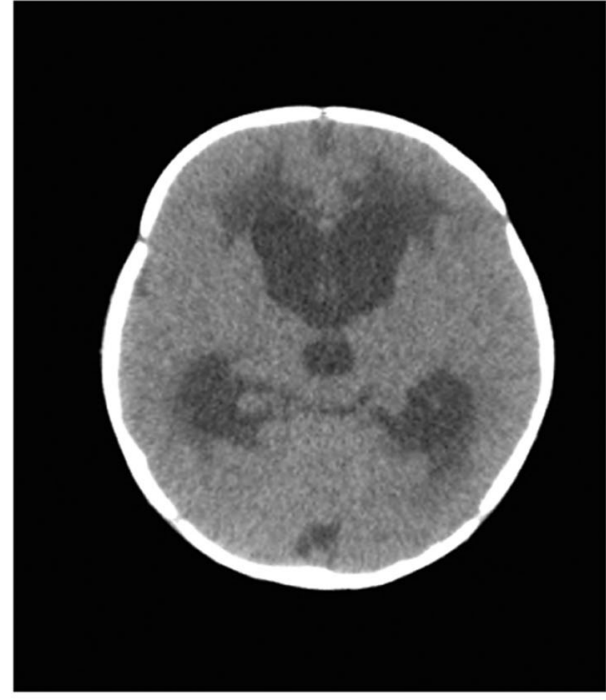

A

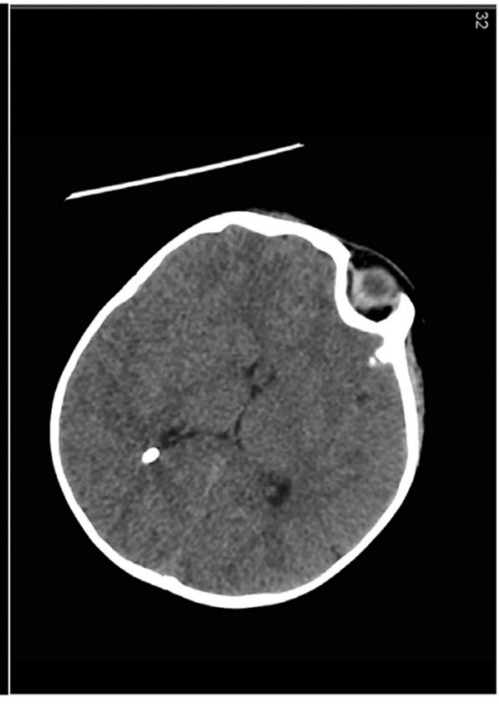

B infiltration into the CNS and confers an increased risk for malignant transformation [5].

\section{Exemplary case description}

A 5-month-old male was delivered via caesarean section at 36-week gestational age. At birth, two extensive congenital hairy nevi had been observed; the first is a giant hairy nevus in bathing trunk distribution and the second $1 \mathrm{~cm}$ wide on the left upper back. Figure 1 illustrates the bathing trunk distribution of the giant nevus.

There were no issues with his feeding, weight gain or neurological development. At 5 months, he presented with a 5 day history of drowsiness, poor feeding, high pitched cry, nausea and vomiting.

His skin was dry and flaky. His mother had mild psoriasis (elbows and knees) and benign moles, but there was no other relevant family history. At the time of presentation, he was alert but irritable, and his anterior fontanel was full and tense. Downward gaze ("setting-sun" sign) was also noticed intermittently but there was no neck rigidity. A non-enhanced computerised tomography (CT) scan demonstrated communicating hydrocephalus and significant transependymal oedema, as illustrated in Fig. 2.

An emergency right ventriculoperitoneal shunt was performed. The patient recovered well from the procedure and was discharged home on postoperative day one. The CSF was xanthochromic and cytological examination revealed medium-sized epithelioid non-pigmented cells with oval nuclei and relatively high nuclear cytoplasmic ratios.
Such appearances have been described in children with NCM [22, 29]. Immunohistochemistry highlighted scattered lymphoid cells (CD45) and epithelioid cells were negative for melanoma markers (MelC, HMB45) as illustrated in Fig. 3.

MR imaging demonstrated meningeal enhancement in the periphery of the left and right cerebellum as well as in the thoracic spine and conus suggestive of melanin deposition. A presumptive diagnosis of NCM was made based on the MR characteristics, CSF cytology and clinical presentation. Follow-up MR 5 months after the procedure showed decompressed ventricles with oedema over the thalamus and diffuse

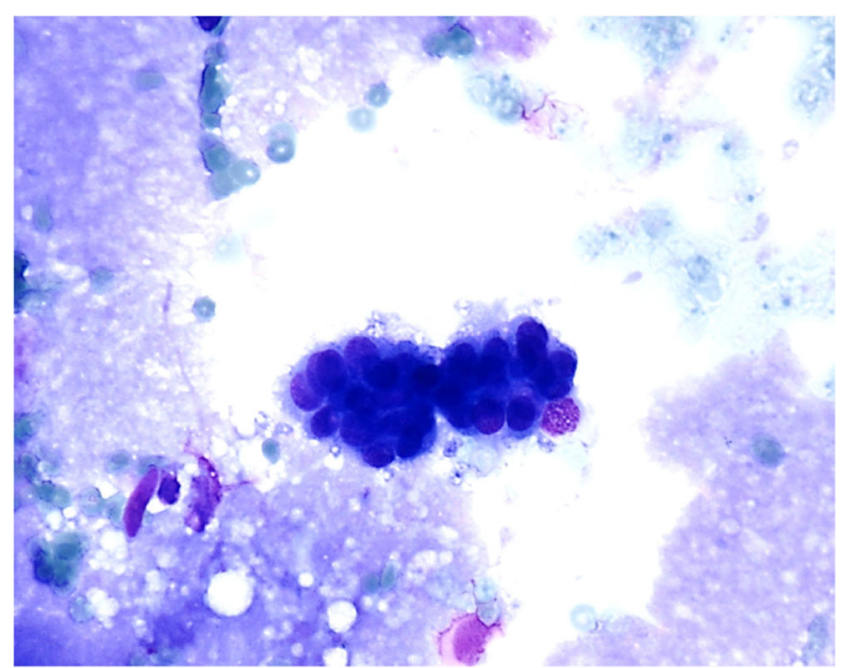

Fig. 3 CSF cytology showing medium-sized epithelioid non-pigmented cells with oval nuclei and relatively high nuclear cytoplasmic ratios 
Fig. 4 a T1-weighted MRI showing diffuse enhancement over the spinal cord again in keeping with CNS melanosis. b Coronal MRI flare image showing decompressed ventricles with oedema over the thalamus

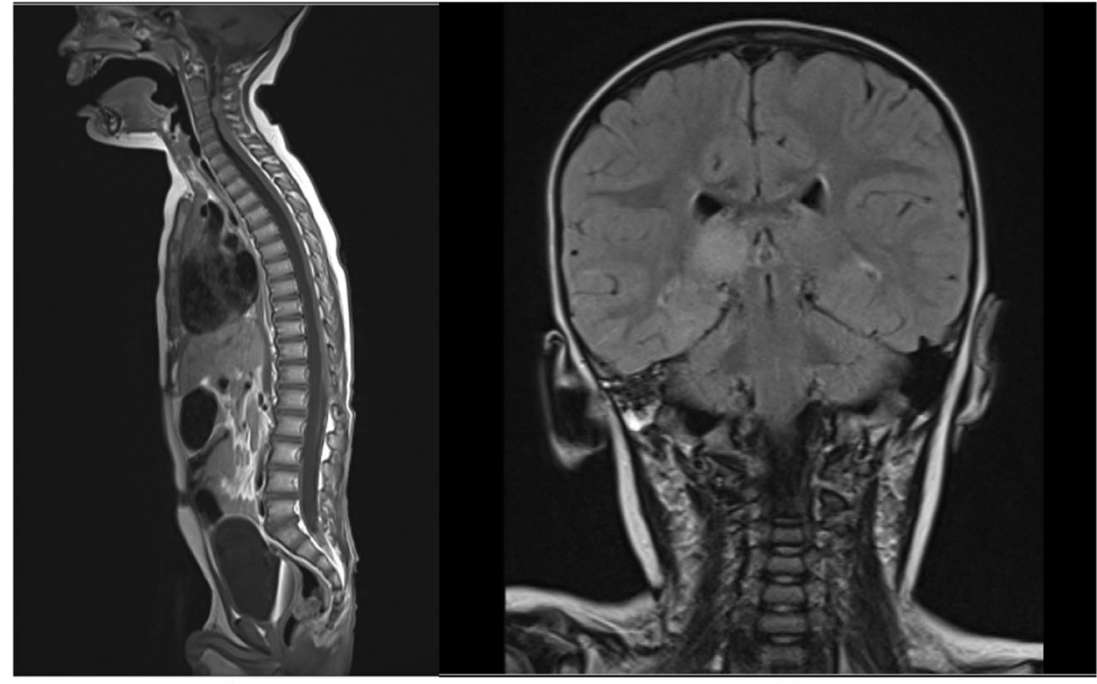

A

enhancement over the spinal cord again in keeping with CNS melanosis, as illustrated in Fig. 4.

At 19 months of age, a repeat MRI showed arachnoid loculations at the ventricular outflow formina as well as thalamic oedema and diffuse spinal enhancement in keeping with NCM. Skin and leptomeningeal biopsies were subsequently taken at 21 months of age which showed N-type Rat Sarcoma gene (NRAS)-mutated melanoma, although PET scan showed no hypermetabolic foci within brain, spine or upper half of the body. For 7 months, he received trametinib, a MAPK/Erk kinase (MEK) inhibitor which inhibits cellular proliferation. During this time, he continued to develop normally and was attaining appropriate social and motor milestones. At 30 months of age, he developed left-sided weakness and status epilepticus requiring PICU admission and ventilator support. No acute changes were demonstrated on head and spine CT. He was extubated successfully but continued to deteriorate neurologically. He received palliative treatment and died at the age of 32 months.

\section{Conclusions}

$\mathrm{NCM}$ is a rare syndrome characterised by congenital melanocytic nevi and melanocytic thickening of the leptomeninges. Cutaneous manifestations of NCM are usually congenital, and neurological manifestations develop early in life. Patients with large or multiple congenital nevi should therefore be investigated early - even in the absence of neurological manifestations - to facilitate treatment plan and prognosis. Because of the uncertain value of CSF cytology, MR imaging is the investigation of choice especially if biopsy cannot be carried out. As in the case reported here, symptomatic NCM usually presents with increased intracranial pressure and hydrocephalus and requires ventriculoperitoneal shunt insertion. Symptomatic NCM is refractory to radiotherapy and chemotherapy and has a poor prognosis. A multidisciplinary approach is necessary in the management of NCM patients. This should include routine neurodevelopmental assessments and dermatologist input.

\section{Compliance with ethical standards}

Conflict of interest The authors certify that they have NO affiliations with or involvement in any organisation or entity with any financial interest or non-financial interest in the subject matter or materials discussed in this manuscript.

Open Access This article is distributed under the terms of the Creative Commons Attribution 4.0 International License (http:// creativecommons.org/licenses/by/4.0/), which permits unrestricted use, distribution, and reproduction in any medium, provided you give appropriate credit to the original author(s) and the source, provide a link to the Creative Commons license, and indicate if changes were made.

\section{References}

1. Acosta FLJR, Binder DK, Barkovich AJ, Frieden IJ, Gupta N (2005) Neurocutaneous melanosis presenting with hydrocephalus: case report and review of the literature. J Neurosurg 102:96-100. https://doi.org/10.3171/ped.2005.102.1.0096

2. Allcutt D, Michowiz S, Weitzman S, Becker L, Blaser S, Hoffman HJ, Humphreys RP, Drake JM, Rutka JT (1993) Primary leptomeningeal melanoma: an unusually aggressive tumor in childhood. Neurosurgery 32:721-729 [discussion: 729]

3. Arai M, Nosaka K, Kashihara K, Kaizaki Y (2004) Neurocutaneous melanosis associated with Dandy-Walker malformation and a meningohydroencephalocele. J Neurosurg 100(Pediatrics 5):501505

4. Barkovich AJ, Frieden IJ, Williams ML (1994) MR of neurocutaneous melanosis. AJNR Am J Neuroradiol 15:859-867

5. Chaloupka JC, Wolf RJ, Varma PK (1996) Neurocutaneous melanosis with the Dandy-Walker malformation: a possible rare pathoetiologic association. Neuroradiology 38:486-489 
6. Cho IY, Hwang SK, Kim SH (2011) Dandy-Walker malformation associated with neurocutaneous melanosis. J Korean Neurosurg Soc 50:475-477

7. Chu WCW, Lee V, Chan Y, Shing MMK, Chik K, Li C, Ma K (2003) Neurocutaneous melanomatosis with rapidly deteriorating course. AJNR Am J Neuroradiol 24:287-290

8. de Andrade DO, Dravet C, Raybaud C, Broglin D, Laguitton V, Girard N (2004) An unusual case of neurocutaneous melanosis. Epileptic Disorders 6:145-152

9. de Wijn RS, Zaal LH, Hennekam RC et al (2010) Familial clustering of giant congenital melanocytic nevi. J Plast Reconstr Aesthet Surg 63:906-913

10. Demirci A, Kawamura Y, Sze G, Duncan C (1995) MR of parenchymal neurocutaneous melanosis. AJNR Am J Neuroradiol 16: 603-606

11. Di Rocco F, Sabatino G, Koutzoglou M, Battaglia D, Caldarelli M, Tamburrini G (2004) Neurocutaneous melanosis. Childs Nerv Syst 20:23-28

12. Fox H (1972) Neurocutaneous melanosis. In: Vinken PJ, Bruyn GW (eds) Handbook of clinical neurology. Elsevier, New York, pp 414-428

13. Frieden IJ, Williams ML (1994) Familial site-specific congenital melanocytic nevus: report of two families. Arch Dermatol 130: 1075-16Ff

14. Frieden IJ, Williams ML, Barkovich AJ (1994) Giant congenital melanocytic nevi: brain magnetic resonance findings in neurologically asymptomatic children. J Am Acad Dermatol 31:423-429

15. Hafner C, Groesser L (2013) Mosaic RASopathies. Cell Cycle 12: $43-50$

16. Hsueh CW, Ho CS, Chiu NC, Shen EY (2004) Neurocutaneous melanosis with hydrocephalus: report of one case. Acta Neurol Taiwanica 13:29-33

17. Iwabuchi T, Shimotake T, Furukawa T, Tsuda T, Aoi S, Iwai N (2005) Neurocutaneous melanosis associated with Hirschsprung's disease in a male neonate. J Pediatr Surg 40:E11-E13. https://doi. org/10.1016/j.jpedsurg.2005.05.030

18. Johnson D, Puzanov I (2016) Treatment of NRAS-mutant melanoma. Curr Treat Options in Oncol 16(4):15. https://doi.org/10.1007/ s11864-015-0330-Z

19. Kadonaga N, Barkovich JA, Edwards MSB, Frieden IJ (1992) Neurocutaneous melanosis in association with the Dandy Walker complex. Pediatr Dermatol 9:37-43

20. Kadonaga N, Frieden J (1991) Neurocutaneous melanosis. Definition and review of the literature. J Am Acad Dermatol 24: 747-755

21. Kinsler VA, Thomas AC, Ishida M, Bulstrode NW, Loughlin S, Hing S, v Chalker J, McKenzie K, Abu-Amero S, Slater O, Chanudet E, Palmer R, Morrogh D, Stanier P, Healy E, Sebire NJ, Moore GE (2013) Multiple congenital melanocytic nevi and neurocutaneous melanosis are caused by postzygotic mutations in codon 61 of NRAS. J Invest Dermatol 133:2229-2236

22. Ko SF, Wang HS, Lui TN, Ng SH, Ho YS, Tsai CC (1993) Neurocutaneous melanosis associated with inferior vermian hypoplasia: MR findings. J Comput Assist Tomogr 17:691-695

23. Makin GW, Eden OB, Lashford LS, Moppett J, Gerrard MP, Davies HA, Powell CV, Campbell AN, Frances H (1999) Leptomeningeal melanoma in childhood. Cancer 86:878-886

24. Marnet D, Vinchon M, Mosto K, Catteau B, Kerdraon O, Dhellemmes P (2009) Neurocutaneous melanosis and the DandyWalker complex: an uncommon but not so insignificant association. Childs Nerv Syst 25:1533-1539

25. McClelland S 3rd, Charnas LR, SantaCruz KS, Garner HP, Lam $\mathrm{CH}$ (2007) Progressive brainstem compression in an infant with neurocutaneous melanosis and Dandy-Walker complex following ventriculoperitoneal shunt placement for hydrocephalus. J Neurosurg 107(6 Suppl Pediatrics):500-503

26. Mena-Cedillos CA, Valencia-Herrera AM, Arroyo-Pineda AI, Salgado-Jimenez MA, Espinoza-Montero R, Martinez-Avalos AB, Perales-Arroyo A (2002) Neurocutaneous melanosis in association with the Dandy Walker complex complicated by melanoma. Pediatr Dermatol 19:237-242

27. Novartis Pharmaceuticals. Study comparing the efficacy of MEK162 versus dacarbazine in unresectable or metastatic NRAS mutation-positive melanoma. IN: ClinicalTrials.gov [Inernet]. Available via DIALOG https://clinicaltrials.gov/show/ NCT01763164 Accessed 26 Aprl 2016. NCT01763164

28. Pavlidou E, Hagel C, Papavasilliou A, Giouroukos S, Panteliadis C (2008) Neurocutaneous melanosis: report of three cases and up-todate review. J Child Neurol 23:1382-1391

29. Peters R, Jansen G, Engelbrecht V (2000) Neurocutaneous melanosis with hydrocephalus, intraspinal arachnoid collections and syringomyelia: case report and literature review. Pediatr Radiol 30:284-288

30. Rhodes RE, Friedman HS, Hutten HP, Hockenberger D, Oakes WJ, Tomita T (1991) Contrast enhancement MR imaging of neurocutaneous melanosis. AJNR Am J Neuroradiol 12:380-382

31. Rokitansky J (1861) Ein ausgezeichneter Fall von Pigment-Mal mit ausgebreiteter Pigmentierung der inneren Hirn- und Rckenmarkshute. Allgem Wien Med Z 6:113-116

32. Sebag G, Dubois J, Pfister P, Brunelle F, Saint-Rose C (1991) Neurocutaneous melanosis and temporal lobe tumor in a child: MR study. AJNR Am J Neuroradiol 12:380-382

33. Shinno K, Nagahiro S, Uno M, Kannuki S, Nakaiso M, Sano N, Horiguchi H (2003) Neurocutaneous melanosis associated with malignant leptomeningeal melanoma in an adult: clinical significance of 5-S-cysteinyldopa in the cerebrospinal fluid-case report. Neurol Med Chir (Tokyo) 43(12):619-625

34. Sung KS, Song YJ (2014) Neurocutaneous melanosis in association with Dandy-Walker complex with extensive intracerebral and spinal cord involvement. J Korean Neurosurg Soc 56(1):61-65

35. Swar MO, Mahgoub SM, Yassin RO, Osman AM (2013) DandyWalker malformation and neurocutaneous melanosis in a threemonth-old infant. Sudanese J Paediatr 13(2):61-65

36. Szathmari A, Perbet R, Hermier M, Di Rocco F, Frappaz D, Mottolese C (2016) Primary amelanotic leptomeningeal melanomatosis in a child: a rare but severe disease. World Neurosurg 92:581.e15-581.e20. https://doi.org/10.1016/j.wneu. 2016.06.039

37. Takayama H, Nagashima Y, Hara M, Takagi H, Mori M, Merlino G, Nakazato Y (2001) Immunohistochemical detection of the c-met proto-oncogene product in the congenital melanocytic nevus of an infant with neurocutaneous melanosis. J Am Acad Dermatol 44: $538-540$

38. Van Bogaert L (1948) La melanose neurocutanee diffuse heredofamiliale. Bull Acad R Belg 13:397-428

39. van Engen-van Grunsven ACH, Kusters-Vandevelde H, Groenen PJTAand. Blokx WAM (2014) Update on molecular pathology of cutaneous melanocytic lesions: what is new in diagnosis and molecular testing for treatment? Front Med 1:39. doi:https://doi.org/10. 3389/fmed.2014.00039

40. Yamazaki Y, Matsuzawa T, Takasugi K, Suzuki N, Kanda M, Kobayashi I (2009) Rapidly progressive and fatal neurocutaneous melanosis presenting as recurrent headache. Paediatr Int 55(2):240 243. https://doi.org/10.1111/j.1442-200X.2012.03653

41. Yoo IH, Yum SK, Oh SJ, Kim KM, Jeong DC (2014) Melanotic neuroectodermal tumor of infancy disseminated by a ventriculoperitoneal shunt and diagnosed from the inguinal sac. J Pediatr Hematol Oncol 36:e61-e64. https://doi.org/10.1097/MPH. 0b013e31829dd114 